DOI: $\underline{\text { https://doi.org/10.24867/12HZ01Bartos }}$

\title{
PRINCIPI UPRAVLJANJA TEKTILNIM OTPADOM I ANALIZA TEHNOLOŠKOG PROCESA RECIKLAŽE TEKSTILA U OPŠTINI BAČKI PETROVAC
}

\section{PRINCIPLES OF TEXTILE WASTE MANAGEMENT AND ANALYSIS OF THE TECHNOLOGICAL PROCESS OF TEXTILE RECYCLING IN THE MUNICIPALITY OF BAČKI PETROVAC}

\author{
Marina Bartoš, Bojan Batinić, Fakultet tehničkih nauka, Novi Sad
}

\begin{abstract}
Kratak sadržaj: Prikazana je analiza uticaja tekstila, njegove proizvodnje, nastanka i korišćenja, principi upravljanja i njegov uticaj na životnu sredinu. Tekstil, kao nevidljivi otpad se godišnje gomila a da još uvek ne postoje dodatne zakonske regulative i rešenja za njegovu minimizaciju kao i reciklažu u većini sveta. U Evropskoj Uniji već postoje zabrane za pojedine vrste tekstila, kao $i$ zakoni za radnu snagu, dok u ostatku sveta $i$ u Republici Srbiji nisu toliko zastupljeni i rigorozni. U radu je opisan sistem upravljanja tekstilnim otpadom u svetu i kod nas, kao i njegovi najveći problemi. Data neka moguća rešenja, kao jedan vid ponovnog korišćenja tekstila. Takođe, opisan je princip upravljanja tekstilnim otpadom u opštini Bački Petrovac, funkcionisanje centra za sakupljanje $i$ reciklažu.
\end{abstract}

Ključne reči: Upravljanje tekstilnim otpadom, tekstil, reciklaža, životna sredina, regulative, stanje u Evropskoj Uniji.

\begin{abstract}
The analysis of the impact of textile, its production, origin and use, management principles and its impact on the environment is presented. Textiles, as invisible waste, accumulate annually without any additional legal regulations and solutions for its minimization as well as recycling in most of the world. In the European Union, there are already bans on certain types of textiles, as well as labor laws, while in the rest of the world and in the Republic of Serbia they are not so represented and rigorous. problems. Some possible solutions are given, as one type of textile reuse. Also, the principle of textile waste management in the municipality of Backi Petrovac, the functioning of the collection and recycling center is described.
\end{abstract}

Keywords: Textile waste management, textiles, recycling, environment, regulations, situation in the European Union

\section{UVOD}

Tekstilna industrija je grana industrije koja se bavi preradom vlaknastih sirovina i izradom tkanina, pletenih proizvoda i prediva.

\section{NAPOMENA:}

Ovaj rad proistekao je iz master rada čiji mentor je bio doc. dr Bojan Batinić.
Oslanja se na poljoprivrednu proizvodnju iz koje crpi potrebne sirovine: vunu, lan, pamuk, svilu, jutu i dr. Ovo je jedna od najstarijih industrijskih grana. Krajnji produkt proizvodnje su odeća i razne vrste tkanina.

Pretpostavlja se da je više od milion tona tekstila godišnje bačeno na deponije. Veći deo tog otpada potiče od domaćinstava. Tekstil čini oko $4 \%$ sadržaja kante za otpad. Oko $50 \%$ tekstila koji se odbaci pogodan je za reciklažu, ali se samo male količine ponovno upotrebe ili recikliraju. Pored domaćinstava, otpad nastaje i u industriji proizvodnje vlakana, proizvodnji odeće, prodaji.

Ako modna industrija ima moć da utiče na trendove, onda takođe ima moć da igra pozitivnu ulogu u zaštiti planete. Eliminisanje toksičnih hemikalija je tek početak. Od brze mode do tekstilnog otpada, potrebna nam je globalna tekstilna industrija da bude pravi ,trendovski pokretač“ i da se zauzme stav o uticaju mode na životnu sredinu i zdravlje ljudi.

\section{TEKSTILNA INDUSTRIJA I NJENA ŠTETA OKOLINI}

Tekstilna industrija se prvenstveno bavi dizajnom, proizvodnjom i distribucijom prediva, tkanina i odeće. Sirovina može biti prirodna ili sintetička, koristeći proizvode hemijske industrije.

Zagađivače, koje oslobađa globalna tekstilna industrija kontinuirano čine nezamislivu štetu okolini. Zagađuje zemlju i dugoročno je čini beskorisnom i neplodnom [5]. Pamuk troši najviše količine štetnih pesticida i đubriva. Većina njih pada na zemlju dok ih prskaju po usevu. Slično tome, proizvodne jedinice za tekstil ispuštaju opasni otpad u obližnje zemljište. Izvršeno je istraživanje za ispitivanje količine metala prisutnih u zemljištu i podzemnim vodama koje se nalaze u blizini tekstilne i kožarske industrije u gradu Haridvar, Indija. Rezultati su pokazali da su svi metali poput hroma, gvožđa, mangana, bakra, olova i kadmijuma bili prisutni u količinama većim od onih koje je propisala Svetska zdravstvena organizacija (SZO). Oni mogu izazvati mnoge probleme kod živih bića. Opasni efekti upotrebe toksičnih đubriva na farmama su najveći u Indiji, Pakistanu i Bangladešu [6]. Tekstilna industrija svakodnevno koristi preko 3.5 miliona litara vode. To je zato što se za proizvodnju $1 \mathrm{~kg}$ tkanine obično potroši 200 litara vode. Kao posledica toga, 20\% zagađenja sveže vode nastaje tretiranjem i bojenjem tekstila. Velike količine vode ispuštene $u$ procesu proizvodnje tekstila odgovorne su za toksičnost 
vodenih organizama. Otpadna voda obično sadrži ftalate, organohlorna jedinjenja, olovo i mnoge druge hemikalije koje uzrokuju teške zdravstvene probleme i bolesti kod ljudi. Industrija bojenja i dorade tekstila stvorila je veliki problem zagađenja, jer je jedna od hemijski najintenzivnijih industrija na zemlji i zagađivač čiste vode. Danas industrija proizvodi više od 3600 boja za tekstil. Industrija koristi više od 8000 hemikalija u različitim procesima proizvodnje tekstila, uključujući bojenje i štampu. Mnoge od ovih hemikalija su otrovne i štetne po ljudsko zdravlje direktno ili indirektno [7].

\section{ZAKONODAVNI OKVIR U EU I REPUBLICI SRBIJI}

Uvedena krajem 2011. godine, ova EU uredba objedinila je tri prethodne uredbe - direktive koje se tiču mešavine vlakana od ternarnih vlakana (73/44 / EEZ), smeše binarnih vlakana (96/73 / EC) i imena tekstila (2008/121/ EC), što znači da su označavanje sadržaja vlakana i testiranje sadržaja vlakana sada spojeni u jedan jedini zakon. Evropska komisija navodi da je odlučila da revizira zakonodavstvo o imenima tekstila kako bi pojednostavila i poboljšala postojeći regulatorni okvir za razvoj i upotrebu novih vlakana, sa ciljem da podstakne inovacije u sektoru tekstila i odeće.

Paket cirkularne ekonomije, usvojen 2018. godine, prvi put će tražiti da države članice osiguraju da se tekstil sakuplja odvojeno [9]. Nova direktiva (Directive (EU) 2018/850/EC on the landfill of waste) o otpadu zahteva od država članica da ih utvrde i pripreme šeme najkasnije do 2025. godine. Takođe, zahteva se da Evropska komisija uzme u obzir to krajem 2024. godine da bi procenili da li bi trebalo uvesti i ciljeve za ponovnu upotrebu i recikliranje tekstilnog otpada. EU takođe postavlja evropske standarde koji se odnose na tekstil i odeću. Neki od standarda se odnose na minimalne zahteve za performanse za određene vrste tekstilnih proizvoda $\mathrm{i}$ ekološke aspekte tekstilnih proizvoda, na primer, evropski standard CEN/TS 16822:2015. Pored toga, EU eko znak za odeću i tekstil, program dobrovoljnog sertifikovanja, uspostavlja ekološke kriterijume koji garantuju ograničenu upotrebu materija štetnih za zdravlje i životnu sredinu, smanjenje zagađenja vode i vazduha, kao i kriterijumi za produženje veka odeće (otpornost na smanjivanje tokom pranja i sušenje i otpornost boje na znojenje, pranje, mokro i suvo trljanje i izlaganje) [10].

Ministarstvo privrede je tokom 2013. godine u pravni sistem Republike Srbije preuzelo evropske direktive "starog pristupa" za obeležavanje tekstilnih proizvoda i označavanje obuće.

Za transponovanje i implementaciju Evropske Uredbe broj 1007/11 i Uredbe 2018/122 nadležno je Ministarstvo privrede - Sektor za kvalitet i bezbednost proizvoda. Ova oblast je regulisana Pravilnikom o izmenama i dopunama pravilnika o označavanju i obeležavanju tekstilnih proizvoda ("Sl. glasnik RS", br. 86/2019) koji je usklađen sa svim načelima i bitnim zahtevima iz Uredbe broj 2018/122 od 20. oktobra 2017. godine Evropske komisije kojom se dopunjava Uredba broj 1007/11 Evropskog parlamenta i Saveta o nazivima tekstilnih vlakana i označavanju i obeležavanju sirovinskog sastava tekstilnih proizvoda. Ministarstvo privrede - Sektor za kvalitet i bezbednost proizvoda, je pripremio i na internet stranici
Sektora Priručnik za primenu Pravilnika, kao pomoć privrednicima, organima tržišnog nadzora i drugim zainteresovanim stranama koje primenjuju propise u ovoj oblasti.

\section{TRENUTNO STANJE UPRAVLJANJA TEKSTILNIM OTPADOM U DANSKOJ I SRBIJI}

Svake godine se stavi na dansko tržište za potrošnju oko 89.000 tona, što odgovara $16 \mathrm{~kg}$ nove odeće i tekstila za domaćinstvo po osobi. Ovaj iznos daje naznaku količine upotrebljenog tekstila koji se generiše svake godine ako se pretpostavljaju stalni uslovi. Različite dobrotvorne i privatne organizacije godišnje odvojeno prikupe oko 41.000 tona. Od odvojeno prikupljenog tekstila, približno 23.000 tona se izvozi za ponovnu upotrebu i reciklažu, a 12.000 tona ponovo se koristi (uz malu količinu recikliranja) u Danskoj. Preostalih 6.000 tona se spaljuje. Sudbina procenjenih 48.000 tona između novog tekstila stavi se na tržište svake godine, a ono što se odvojeno prikuplja nakon upotrebe, može se okvirno proceniti korišćenjem podataka iz ankete o otpadu potkrepljenih pretpostavkama [12].

Kolekcijom polovnog tekstila dominiraju četiri velika kolekcionara: dobrotvorne organizacije Armija spasa (7.500 tona/god.), Danski Crveni krst (6.000 tona/god.), Danchurch Social (5.000 tona/god.) I jedan privatni glumac, Trasborg (7.000 tona/god.). Postoje i dva manja, ali i dalje vredna pažnje kolektora UFF (1.700 tona/god.) I Danmission (1.000 tona/god.). Zajedno sa ovim organizacijama postoji veliki broj manjih aktera (procenjuje se da ukupno ima oko 25 aktera) koji čine preostalih $40 \%$ danskog tržišta kolekcije. Ako sakupljač sakuplja putem kontejnera u javnom prostoru ili u centru za reciklažu otpada, mora da dobije dozvolu od opštine. Stoga su opštine ključni akteri na tržištu. Druga opcija je postavljanje kontejnera na privatno zemljište, npr. pored supermarketa, u kom slučaju sakupljaču treba dozvola vlasnika zemljišta. U Danskoj je zanemarivo recikliranje tekstilnog otpada. Korišćeni tekstil se može prodati u više različitih kategorija prema nivou sortiranja, kvalitetu, vlaknima i tako dalje. Kupac tako može uzeti seriju nerazvrstanih tekstila, seriju polurazvrstanih tekstila od kojih je razvrstan tekstil pogodan za dansku ponovnu upotrebu ili serije sortiranih tekstila poput vunenih zimskih kaputa, pamučne dečije odeće itd., U zavisnosti od sporazuma. Generalno, cena korišćenog tekstila zavisi od kvaliteta tekstila u datoj frakciji i stepena sortiranja.

U Srbiji su prikupljanje i prerada tekstilnog otpada na simboličnom nivou, regulativa je nedorečena a uspešne priče ne dolaze iz komercijalnog sektora, već iz socijalnog preduzetništva. Procenjuje se da tekstilni otpad u Srbiji čini oko 5\% komunalnog otpada, što znači da se otprilike godišnje baci oko 100 hiljada tona odeće, obuće i kućnog tekstila [11].

Domaći projekat ReTex je osmišljen u „Ženskom centru Užice“, kao inovativni centar za prikupljanje i reciklažu tekstila. Prvo je formiran servis za prikupljanje, sortiranje i doniranje upotrebljiivog tekstila, a potom i radionica za proizvodnju galanterije od recikliranog tekstila. Servis je u proteklih osam godina uspeo da prikupi 21.000 komada tekstila, i da sortira 60 tona za reciklažu, a njegove usluge koristi oko 280 socijalno ugroženih porodica, dok se u 
radionici izrađuju korporativni pokloni i suveniri od recikliranog tekstila. Najveća prepreka za efikasnije iskorišćavanje tekstilnog otpada u Srbiji svakako leži u neorganizovanom prikupljanju. Osim ReTexa, koji poseduje tri specijalizovana kontejnera na teritoriji Užica, u drugim lokalnim samoupravama ostavljeno je komunalnim preduzećima na volju da li će i kako sortirati tekstilni otpad. U Beogradu je taj zadatak na sebe preuzela „Gradska čistoća“, koja je u poslednje tri godine postavila 41 kontejner za tekstilni otpad, a na portalu ovog javno-komunalnog preduzeća može se saznati i da je spremno da proda prikupljene količine za pet dinara po kilogramu [1].

\section{Upravljanje tekstilnom industrijom u opštini Bački Petrovac}

Opština Bački Petrovac je opština koja se nalazi u AP Vojvodini, i nalazi se u južnom delu Bačke. Obuhvata četiri naselja, Bački Petrovac, Gložan, Maglić i Kulpin. Površine je 158 kilometara kvadratnih, u okviru kojih živi 14.681 stanovnika.

S obzirom da je opština Bački Petrovac pretežno okrenuta poljoprivredi, biorazgradiv otpad je dominantan, dok tekstilni otpad čini samo 5.3\%. Samo mali procenat tekstilog otpada završava na deponiji, dok se većinom iznošena odeća predaje humanitarnim organizacijama. Danas, na teritoriji opštine Bački Petrovac, postoje dve zanatsko trgovinske radnje, koje se bave dizajniranjem i prodajom sopstvene odeće, dok materijal nabavljaju iz Turske. Takođe, u okviru opštine postoji i centar za sortiranje i baliranje škart odeće.

Zanatsko trgovinske radnje se bave proizvodnjom i prodajom odeće na teritoriji opštine Bački Petrovac duži niz godina. Sav tekstil se iskoristi maksimalno, dok se samo delići tkanina bacaju. Tekstilni otpad se baca u kante zajedno sa komunalnim otpadom, koji završi na deponiji, ili se spaljuje.

\section{RECIKLAŽA TEKSTILA}

Reciklaža tekstila je postupak kojim se stara odeća i drugi tekstil oporavlja radi ponovne upotrebe ili oporavka materijala. To je osnova za industriju reciklaže tekstila. Glavna prednost aktivnosti recikliranja tekstila je mogućnost ponovne upotrebe odeće. Kroz ponovnu upotrebu odeće i tekstila možemo izbeći zagađenje i energetski intenzivnu proizvodnju nove odeće. Pored toga, odeća koja se ne može ponovo upotrebiti može se prebaciti u proizvode kao što su krpe ili reciklirani u tkaninu ili drugi materijal za preradu [3].

U Sjedinjenim Državama svake godine nastaje više od 15 miliona tona polovnog tekstilnog otpada, a količina se udvostručila u poslednjih 20 godina. [4] U 2014. godini proizvedeno je preko 16 miliona tona tekstilnog otpada, prema podacima Agencije za zaštitu životne sredine. Od ovog iznosa reciklirano je 2.62 miliona tona, 3.14 miliona tona je sagorelo za povrat energije, a 10.46 miliona tona je poslato na deponiju. Prosečni Amerikanac godišnje baci oko 80 kilograma iskorišćene odeće. Više od $70 \%$ svetske populacije koristi iskorišćenu odeću. Oko 50 procenata prikupljene obuće i odeće koristi se kao iskorišćeni proizvodi. U međuvremenu, $20 \%$ se koristi za proizvodnju krpa za poliranje i čišćenje raznih industrijskih namena, a $26 \%$ se reciklira za primene kao što su vlakna za izolacione proizvode, presvlake, fiberglas i madraci. Recikliranje tekstila nudi sledeće prednosti za životnu sredinu:

- Smanjuje zahteve za prostorom odlagališta, imajući u vidu da se proizvodi od sintetičkih vlakana ne raspadaju i da prirodna vlakna mogu oslobađati gasove staklene bašte

- Izbegavanje upotrebe primarnih vlakana

- Smanjena potrošnja energije i vode.

\section{Reciklaža tekstila u opštini Bački Petrovac}

$\mathrm{Na}$ teritoriji opštine Bački Petrova se nalazi centar za sakupljanje i baliranje tekstila. Tu se obično odlaže tekstil iz čarapara koje se nalaze u Čelarevu i Mladenovu. Centar prima tekstil isključivo od firmi koja imaju potpisan ugovor sa njima, dok neko bez ugovora ne može da odloži tekstil.

Centar je konstruisan tako da sav tekstil koji se čuva u skladištu budem sklonjen od uslova spoljašnje sredine, kao i da ne dođe do požara. Ali, veći deo tekstila se nalazi svugde okolo centra, odnosno napolju je uskladišten kao veća deponija. U centar se dovozi sav tekstil, iskorišćen, neiskorišćen, sa greškama. A jedino što se iskoristi je beli odnosno ne obojeni tekstil. Najpre se tekstil ručno sortira i odstrani se sav obojeni tekstil, ali i pamuk. Tako sortiran i izdvojen poliamid, ide u mašinu za sečenje tekstila [2]. Iz mašine za sečenje, pod silom potiska tekstil struji u još jednu mašinu gde se opet seče na još sitnije deliće. U toj mašini se nalazi i filter, gde ostale krupne delove, kao i prah odsrani, tako što oni pod silom gravitacije padaju nadole a sakupljaju se u vreće. Zatim, preko vibracione trake nastavlja put u posudu, u koju dolazi ohlađena voda iz ,čilera“. U toj posudi se podešava temperatura na 160260 stepeni Celzijusa, u zavisnosti od materijala. U posudi se tkanina prokuvava, a voda iz posude se vraća nazad u čiler i hladi. Poliamid opet odlazi na sečenje, gde već ostaje plastificiran i u komadićima prečnika između 2,5-3 milimetara.

\section{MOGUĆA REŠENJA}

Odabir ekološke tkanine je složen jer postoje prednosti i nedostaci za sve vrste vlakana. Odeća koja je označena kao načinjena od prirodnih vlakana nije nužno bolja od sintetičke, jer je izbor vlakana samo jedan deo složene slike. Vlakna još uvek moraju da se vrte, pletu ili tkaju, farbaju, dovršavaju, šivaju i prevoze - a sve to imaju različite uticaje na životnu sredinu. Procene pokazuju da ako se u proseku udvostruči broj nošenja odeće, GHG emisije bi bile $44 \%$ niže. U tom pravcu je razvijeno nekoliko koncepata:

- Spora moda. Za razliku od brze mode, spora moda je pokušaj ubeđivanja potrošača da kupuju manje odeće boljeg kvaliteta i da ih duže čuvaju. Poziva na promenu ekonomskog modela, ka prodaji manje odeće.

- Moda kao usluga. Novi poslovni modeli bi mogli povećati broj trošenja određene stavke koristeći principe ekonomije deljenja. Neki brendovi već postoje ponuditi odeću kao uslugu - iznajmljivanje njihove odeće, umesto da je prodaju.

- Poboljšana kolekcija za ponovnu upotrebu, popravku i nadogradnju. 
- Pametna i trenutna moda. Budućnost bi mogla doneti trenutnu i pametnu modu koja bi smanjila otpad dramatično. Pametna moda mogla bi doneti odeću budućnosti koja će možda koristiti pametne tehnologija za trenutno prilagođavanje željama potrošača, promenom boja za na primer, što bi takođe smanjilo potrebu za proizvodnjom više verzija iste odeća.

Napori u poboljšanju odeće zahtevaju prihvaćanje od strane potrošača, sa mogućnostima za nekoliko načina akcije.

- Podizanje svesti potrošača. Kroz kampanje ili pružanje informacija o održivosti u prodavnicama ili putem oznaka na odeći moguće je edukovati potrošače da kupuju samo ono što im je potrebno i biraju održivije opcije. Istraživanja pokazuju da se potrošači uglavnom zalažu za životnu sredinu, ali da se to ne mora nužno odražavati na njihovo stvarno ponašanje.

- Povećana transparentnost i obeležavanje životne sredine. Neke kompanije već potrošačima pružaju informacije o uticaju na životnu sredinu, kao što su emisija $\mathrm{CO}_{2}$ ili upotreba vode. Odabirom održivije opcije moglo bi se doći lakše kroz jasno i standardizovano označavanje ekološki prihvatljivih proizvoda. EU već ima EU eko znak za tekstil i odeću.

- Bolje upute za pranje i sušenje. Kako pranje i sušenje čine veliku količinu doprinos uticaju odeće na životnu sredinu, industrija bi mogla da pomogne pružanje potrošačima bolje informacije o tome kako da smanje taj uticaj za na primer na nalepnicama za negu. Drugi nude postupne smernice za popravku i negu veb stranice.

\section{ZAKLJUČAK}

Modna industrija je ključna za ekonomski razvoj: vrednuje se oko 24 milijarde USD širom i direktno zapošljavaju 75 miliona ljudi u njenom lancu vrednosti. To je treći po veličini proizvodni sektor na svetu nakon automobilske i tehnološke industrije. Ovo stvara izazov proizvođačima odeće da rastu, a da nisu neprijatelji okoline, da postanu saveznici klime, a istovremeno promovišu bolje uslove za radnike u ovom sektoru. Cilj je istražiti upotrebu novih materijala kako bi odeća postala trajnija kako bi se mogla preprodati ili reciklirati u druge proizvode, pomažući smanjenju zagađenja. Neke vodeće marke odgovorile su na ovaj poziv i rade na pronalaženju alternativa vlaknima i razvoju ekološki prihvatljivijih procesa.

U Srbiji čini oko 5\% komunalnog otpada, što znači da se otprilike godišnje baci oko 100 hiljada tona odeće, obuće i kućnog tekstila. Iako su u nekim gradovima postavljeni kontejneri za tekstil, on se i dalje odlaže na deponije a manji deo se iskoriti. U opštini Bački petrovac dolazi veliki deo tekstilnog otpada, ali se samo beli tekstil reciklira i prerađuje, dok se ostali samo skladišti, što je nedovoljno, jer odbačeni deo predstavlja problem po okolinu.

\section{LITERATURA}

[1] Rilak M. (2018), Tekstilni otpad: Drugi život odbačenog tekstila

[2] Snowbob: Kakva je tkanina poliamid. Poliamid (2019)

[3] LeBlanc R. (2019) The basic of textile recycling

[4] LeBlanc R. (2019), Textile and garment recycling fact and figures
[5] Fibre2Fashion (2012), Various Pollutants Released into Environment by Textile Industry

[6] World Bank (2014), The Bangladesh Responsible Sourcing Initiative A NEW MODEL FOR GREEN GROWTH

[7] Kant R. (2012), Textile dyeing industry an environmental hazard

[11] South-East European Industry (2017), Textile industry in Serbia

[9] Official Journal of the European Union (2011), REGULATION (EU) No 1007/2011 OF THE EUROPEAN PARLIAMENT AND OF THE COUNCIL [10] Jacometti V. (2019), Cirkular economy and waste in the fashion industry

[11] Urošević S., Đorđević D., Cvijanović J. M. (2009), Značaj doradnih poslova za razvoj tekstilne i odevne industrija Srbije u procesu tranzicije

[12] Palm D., Elander M., Watson D., KiørboeN. Salmenperä H., Dahlbo H., MoliisK., Lyng K., Valente C., Gíslason S., Tekie H. and Rydberg T. (2014), Towards a Nordic textile strategy Collection, sorting, reuse and recycling of textiles

\section{Kratka biografija}

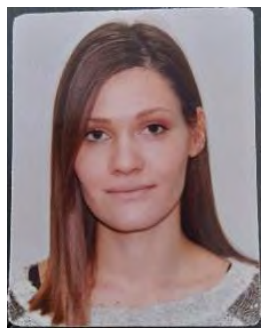

Marina Bartoš je rođena 6. juna 1996. godine u Gložanu. Osnovnu školu je završila u Gložanu, a srednju tehničku školu „Pavle Savićc“ u Novom Sadu 2015. godine. Fakultet tehničkih nauka, smer inženjerstvo zaštite životne sredine je upisala 2015. godine a osnovne akademske studije završila 2019. godine. Master studije na Fakultetu tehničkih nauka, smer inženjerstvo zaštite životne sredine, je upisala 2019. godine.

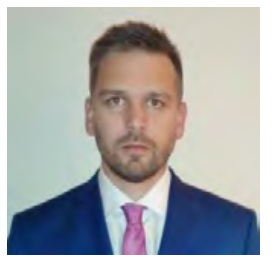

Bojan Batinić (1981) je docent na Fakultetu tehničkih nauka - Departmanu za inženjerstvo zaštite životne sredine u Novom Sadu. Dosadašnji naučnoistraživački rad orijentisan je na analizu fizičko-hemijskih karakteristika komunalnog otpada, modelovanje i projekciju budućih karakteristika otpada, analizu sistema sakupljanja i transporta otpada, mogućnosti iskorišćenja posebnih tokova otpada i sl. Stečena stručna znanja implementirao je kroz učestvovanje na preko 35 projekata saradnje sa privredom iz oblasti zaštite životne sredine i upravljanja otpadom. Rezultate svog naučno istraživačkog rada publikovao je kroz 11 radova u međunarodnim časopisima sa SCI liste, kao i preko 50 saopštenja na skupovima međunarodnog i nacionalnog značaja. 